\title{
PENGEMBANGAN MULTIMEDIA PEMBELAJARAN TATA RIAS WAJAH KOREKTIF
}

\author{
Maya Masitha Astriani
}

FTMIPA Universitas Indraprasta PGRI maya.masitha@gmail.com

\begin{abstract}
Abstrak
Penelitian ini bertujuan untuk: (1) menghasilkan multimedia pembelajaran tata rias wajah korektif yang layak digunakan dalam proses pembelajaran, (2) mengetahui efektivitas produk multimedia pembelajaran tata rias wajah korektif dalam meningkatkan pengetahuan dan keterampilan mahasiswa. Metode penelitian yang digunakan adalah metode penelitian dan pengembangan $(R \& D)$ dengan model pengembangan Dick, Carey dan Carey, dan model CAI. Prosedur pengembangan multimedia meliputi tahap desain, pengembangan dan evaluasi. Teknik analisis data untuk uji coba produk menggunakan statistik deskriptif. Hasil penelitian sebagai berikut. (a) Multimedia yang dikembangkan dinilai layak digunakan dalam pembelajaran ditinjau dari aspek media dan materi. Kelayakan tersebut dapat dilihat dari skor penilaian ahli media 3,54 dengan kategori baik dan skor ahli materi 3,60 dengan kategori baik. (b) Multimedia pembelajaran tata rias wajah korektif dinilai efektif karena dapat meningkatkan pengetahuan dan keterampilan. Hal ini dibuktikan melalui hasil nilai pre-test aspek kognitif dengan rata-rata nilai 53,13 dan nilai post-test dengan rata-rata nilai 80,62 . Hasil nilai pre-test ranah psikomotorik dengan rata-rata nilai 76,72 dan nilai post-test dengan rata-rata nilai 81,01 .
\end{abstract}

Kata kunci: Multimedia, pembelajaran, tata rias wajah korektif

\begin{abstract}
This research aims to: (1) product learning multimedia corrective make up feasibility used in learning, (2) know the effectiveness of multimedia learning product corrective make up in increasing students knowledge dan skill. This research was a research development $(R \& D)$ with the development model by Dick, Carey and Carey, and CAI model. The development procedure includes the design, development and evaluation. The data of the try-out of the product was analyzed using descriptive statistics. The results of the study are as follows. (a) Multimedia learning developed is judged worthy tobe used as a learning in terms of media and materials. The feasibility can be seen from the expert assessment score of 3,54 in media with the good category, and score of 3,60 in material with category good. (b) Multimedia learning corrective make up is considered effective because it can increase students knowledge and skill. This is evidenced by the result of the pre-test aspect cognitive with an average value of 53,13 and post-test value with an average value of 80,62. The result of the pre-test aspect psycomotoric with an average value of 76,72 and post-test value with an average value of 81,01 .
\end{abstract}

Keywords: multimedia, learning, corrective make up 


\section{PENDAHULUAN}

Menurut undang-undang No. 20 tahun 2003 Bab 1 pasal 1, tentang Sistem Pendidikan Nasional, hakekatnya pembelajaran adalah proses interaksi peserta didik dengan pendidik dan sumber belajar pada suatu lingkungan belajar. Dalam pengertian ini yang menjadi fokus adalah peserta didik. Ini berarti bahwa dalam kegiatan pembelajaran yang diutamakan adalah bagaimana para peserta didik dapat berinteraksi dengan pendidik dan sumber belajar agar potensi yang dimilikinya dapat berkembang secara optimal dalam suatu lingkungan belajar yang dapat mendukung interaksi berjalan secara baik dan efektif.

Dalam pembelajaran di perguruan tinggi, tugas utama dosen adalah bagaimana agar para mahasiswanya belajar, dengan cara mengatur elemenelemen inti pembelajaran sedemikian rupa sehingga benar-benar mendukung proses belajar yang dilakukan mahasiswa. Elemen-elemen penting yang dimaksud adalah komponen-komponen pembelajaran, yang dalam terminologi teknologi pendidikan disebut dengan media pembelajaran. Media pembelajaran baik yang dirancang (by design) maupun yang dimanfaatkan (by utilization) untuk keperluan pembelajaran. Upaya menyediakan media pembelajaran ini dapat dilakukan dengan cara menciptakan sendiri media pembelajaran yang benar-benar baru, dapat pula dilakukan dengan memberikan informasi yang diperlukan untuk mendapatkan media pembelajaran tersebut. Media atau bahan sebagai sumber belajar merupakan komponen dari sistem instruksional di samping pesan, orang, teknik latar dan peralatan (Sadiman dkk, 2009: 19).

Kemajuan teknologi membuat manusia secara sengaja atau tidak sengaja telah dan akan berinteraksi dengan teknologi. Media elektronik sebagai akibat dari perkembangan teknologi, mendapat tempat dan perhatian yang cukup besar bagi para peserta didik dan besar pengaruhnya terhadap perkembangan pendidikan.

Manfaat aktivitas dalam pembelajaran yang disebabkan oleh kemajuan ilmu pengetahuan dan teknologi adalah agar mahasiswa dapat mencari sendiri dan langsung mengalami proses belajar. Belajar yang dimaksud berupa pembelajaran yang dilaksanakan secara realistik dan konkrit, sehingga mengembangkan pemahaman dan berpikir kritis serta menghindari terjadinya verbalisme yang terus menerus. Penyampaian materi pembelajaran yang tidak bervariasi dapat menjadi penyebab tidak tercapainya tujuan pembelajaran yang diinginkan. Dengan adanya variasi dalam pembelajaran diharapkan mahasiswa dapat mandiri yang pada akhirnya akan mengembangkan seluruh aspek pribadi.

Dari hasil pengamatan terlihat bahwa proses pembelajaran yang diselenggarakan oleh program studi Tata Rias Universitas Negeri Jakarta hampir semuanya bersifat pasif karena dosen memberikan materi kuliah atau praktikum sementara mahasiswa hanya menerima materi kuliah, kemampuan praktek terbatas, serta kurangnya belajar secara individual yang mengarah pada pengembangan keterampilan.

Tata rias wajah korektif merupakan salah satu mata kuliah yang wajib diambil oleh mahasiswa program studi Tata Rias Universitas Negeri Jakarta. Mata kuliah ini memiliki bobot 2 SKS, dimana $60 \%$ merupakan teori dan $40 \%$ merupakan praktek. Tujuan mata kuliah ini agar mahasiswa memiliki pengetahuan, pemahaman dan keterampilan tentang tata rias wajah. Materi mata kuliah tata rias wajah korektif meliputi konsep dasar tata rias wajah; alat, kosmetika dan bahan untuk tata rias wajah; prinsip dan 
langkah-langkah tata rias wajah, bentukbentuk wajah dan cara mengoreksinya, bentuk-bentuk bagian wajah (alis, mata, hidung, bibir) dan cara mengoreksinya; rias wajah sehari-hari; rias wajah pagi; rias wajah pesta; dan rias wajah malam (Supiani: 2013).

Secara khusus dari penelitian pendahuluan dilakukan dengan menyebarkan angket kepada 32 orang mahasiswa Tata Rias. Dari angket diperoleh data bahwa pada pemahaman dan pengaplikasian koreksi bentuk wajah dan bentuk bagian wajah sebanyak 20 orang $(62,5 \%)$ menyatakan kurang memahami dan mengaplikasikannya, 6 orang $(18,75 \%)$ menyatakan cukup dan 6 orang $(18,75 \%)$ menyatakan sangat memahami dan mengaplikasikan. Penyebab materi pembelajaran sulit dipahami menurut 20 orang $(62,5 \%)$ karena kurang contoh aplikasi dari materi, sebanyak 7 orang $(21,87 \%)$ menyatakan materi terlalu abstrak dan tidak sistematis, sebanyak 3 orang $(9,38 \%)$ menyatakan belum menggunakan media pembelajaran yang tepat, dan sebanyak 2 orang $(6,25 \%)$ menyatakan cara penyampaian dosen kurang jelas.

Dari wawancara informal dengan dosen mata kuliah tata rias wajah korektif diketahui bahwa pembelajaran tata rias wajah korektif masih mengandalkan dosen sebagai satu-satunya sumber informasi untuk setiap materi yang diajarkan. Dosen pula yang harus meluruskan jika ada kekeliruan pemahaman dan kesalahan praktek yang dilakukan mahasiswa. Dari observasi yang dilakukan dalam pembahasan materi bentuk wajah dan bentuk bagian wajah serta koreksinya dilakukan sebatas teori dan hanya diberi contoh sesuai dengan bentuk wajah yang ditemui pada model yang ditampilkan dan kurang contoh aplikasi untuk koreksi bentuk wajah dan bentuk bagian wajah yang lain. Hal ini menyebabkan mahasiswa kesulit- an memahami materi, padahal materi bentuk wajah dan bentuk bagian wajah serta koreksinya merupakan teknik dasar yang akan dipakai saat melakukan rias wajah yang lebih beranekaragam dan menjadi hal yang beresiko dalam dunia pekerjaan jika salah diaplikasikan.

Dalam waktu pelaksanaan perkuliahan yang rata-rata tidak lebih dari 2 SKS setiap kali pertemuan, kurang memberi kesempatan mahasiswa dalam memahami dengan baik materi yang dipelajari, sedangkan setiap mahasiswa memiliki kemampuan berbeda-beda dalam memahami materi. Media penyampaian materi bentuk wajah dan bentuk bagian wajah serta koreksinya berupa gambar yang kurang realistik yang berasal dari buku cetak. Gambar tersebut disajikan dalam powerpoint yang akan dijelaskan oleh dosen. Selain itu, mahasiswa malas mempelajari materi dari buku modul yang diberikan. Pada pelaksanaan praktek mahasiswa masih terdapat kekurangan dari segi korektif bentuk wajah dan bentuk bagian wajah. Adanya kecenderungan dalam pembelajaran mata kuliah praktek, pembahasan teori yang mengiringi pembelajaran kurang mendapat perhatian yang semestinya.

Beberapa masalah tersebut dapat menghambat pembelajaran tata rias wajah korektif, maka sebagai salah satu solusinya dibutuhkan sebuah media pembelajaran pendukung agar dapat membantu mahasiswa untuk memahami dan mendalami materi yang dipelajari serta diharapkan mampu memberikan kemudahan bagi mahasiswa dalam mencapai tujuan pembelajaran.

Kata media merupakan bentuk jamak dari medium, yang berarti komunikasi dan berasal dari bahasa Latin medium ("perantara"), yang merujuk pada segala sesuatu yang mengantar informasi antara sumber pesan dan penerima pesa (Smaldino dkk: 2008). 
Sedangkan menurut Miarso (2004), media pembelajaran adalah segala sesuatu yang digunakan untuk menyalurkan pesan serta dapat merangsang pikiran, perasaan, perhatian dan kemauan belajar sehingga dapat mendorong terjadinya proses belajar yang disengaja, bertujuan dan terkendali. Dari kedua pendapat tersebut dapat disimpulkan bahwa media pembelajaran adalah segala sesuatu yang dapat digunakan untuk menyalurkan pesan dalam pembelajaran agar peserta didik dapat menerima informasi sehingga terjadi proses belajar dalam dirinya.

Salah satu jenis media pembelajaran yang dapat digunakan adalah multimedia pembelajaran. Menurut Vaughn (2006: 4), multimedia merupakan kombinasi antara teks, seni grafis, suara, animasi, dan video yang disampaikan melalui komputer atau peralatan elektronik. Multimedia tidak sekedar menampilkan teks dan gambar, melainkan media yang mampu menampilkan suara, animasi, video serta umpan balik (feed back) secara langsung yang dapat digunakan secara interaktif. Multimedia diharapkan dapat mengurangi verbalisme dalam pembelajaran, mengurangi kejenuhan, meningkatkan motivasi dalam menemukan informasi, serta dapat digunakan sebagai media pembelajaran baik bagi dosen maupun mahasiswa.

Dengan multimedia pembelajaran ini peran dosen lebih ke arah mengawasi, mengontrol dan mengevaluasi kegiatan belajar yang dilakukan mahasiswa. Beberapa format penyajian multimedia diantaranya tutorials, drill and practice, simulations, Instructional games dan hybrid, multimedia sangat cocok jika digunakan untuk menyampaikan materi pelajaran yang bersifat aplikatif atau praktek yang membutuhkan informasi tambahan (Hannafin dan Peck: 1988).
Masalah belajar yang terjadi pada mahasiswa tata rias dapat dipecahkan dengan bantuan dan peran serta Teknologi Pendidikan, melalui pengembangan multimedia pembelajaran yang berisikan materi bentuk wajah dan bentuk bagian wajah serta koreksinya bagi mahasiswa tata rias. Multimedia pembelajaran dapat digunakan oleh seluruh mahasiswa tata rias dan melengkapi keterbatasan pembelajaran yang selama ini dilaksanakan serta membantu setiap mahasiswa memperdalam pengetahuan dan pemahaman, sehingga diharapkan kualitas keterampilan setiap mahasiswa akan maksimal.

\section{METODE PENELITIAN}

Penelitian ini menggunakan metode penelitian R\&D (Research and Development) dengan pendekatan kualitatif yang bertujuan menghasilkan produk berupa multimedia pembelajaran yang layak dan berkualitas untuk kegiatan pembelajaran tata rias wajah korektif. Penelitian dilaksanakan di program studi Tata Rias Universitas Negeri Jakarta dengan subjek penelitian sebanyak 29 orang mahasiswa yang sedang mengambil mata kuliah Tata Rias Wajah Korektif. Model pengembangan yang digunakan adalah model pengembangan instruksional oleh Dick, Carey dan Carey, dan model pengembangan produk pembelajaran berbasis komputer (Computer Assisted Instruction) oleh Hannafin dan Peck.

Tahapan yang ada dalam model pengembangan instruksional oleh Dick, Carey dan Carey (2005) diantaranya: 1) Mengidentifikasi tujuan pembelajaran umum (identify instructional goal); 2) Melakukan analisis pembelajaran (conduct instructional analysis); 3) Mengidentifikasi perilaku dan karakteristik peserta didik (analyze learners and contexts); 4) Merumuskan 
tujuan pembelajaran khusus (write performance objectives);

Mengembangkan butir tes acuan patokan (develop assessment instruments) atau mengembangkan instrumen penilaian); 6) Mengembangkan strategi pembelajaran (develop instructional strategy); 7) Mengembangkan dan memilih materi pembelajaran (develop and select instructional materials); 8) Mendesain dan melaksanakan evaluasi formatif (design and conduct formative evaluation of instruction). Evaluasi formatif dilaksanakan dengan pengumpulan data yang digunakan untuk mengidentifikasi bagaimana memperbaiki kualitas media pembelajaran; 9) Merevisi kegiatan pembelajaran (revisi instruction). 10) Desain dan pelaksanaan evaluasi sumatif (design and conduct summative evaluation). Dalam penelitian ini dilakukan hanya sampai langkah ke-9 dan evaluasi formatif dilakukan dengan melibatkan ahli media, ahli materi, uji coba satu-satu (one to one try-out), uji coba kelompok kecil dan uji coba lapangan (field try-out).

Tahapan yang ada dalam model pengembangan produk pembelajaran berbasis komputer (Computer Assisted Instruction) oleh Hannafin dan Peck (1988) meliputi analisis kebutuhan (needs assessment), disain (design), pengembangan dan implementasi (develop and implement), serta setiap tahap selalu melewati tahap evaluasi dan revisi (evaluation and revise).

Instrumen yang digunakan dalam penelitian ini berupa angket dan tes yang telah divalidasi. Angket digunakan untuk memperoleh data hasil evaluasi media pembelajaran oleh ahli media, ahli materi, uji coba satu-satu, dan uji coba kelompok kecil. Sedangkan tes digunakan untuk memperoleh data efektivitas pembelajaran pada uji coba lapangan dengan menggunakan media pembelajaran yang telah dikembangkan.
Teknik analisis data dalam penelitian ini menggunakan statistik deskriptif yang berupa pernyataan sangat baik, baik, cukup, kurang, sangat kurang yang diubah menjadi data kuantitatif dengan skala 5 yaitu dengan penskoran dari 1-5. Langkah-langkah dalam analisis data antara lain: (1) mengumpulkan data mentah; (2) pemberian rata-rata skor; (3) skor dikonversikan menjadi nilai dengan skala 5 dengan menggunakan acuan konversi (Sukardjo: 2008) seperti yang terdapat pada tabel 1. Acuan penilaian tersebut digunakan untuk menentukan kriteria layak tidaknya produk multimedia yang dikembangkan.

Tabel 1. Kriteria penilaian pada skala 5

\begin{tabular}{ccc}
\hline Nilai & Rentang & Kategori \\
\hline 5 & $\mathrm{X}>4,08$ & Sangat Baik \\
\hline 4 & $3,36<\mathrm{X} \leq 4,08$ & Baik \\
\hline 3 & $2,64<\mathrm{X} \leq 3,36$ & Cukup \\
\hline 2 & $1,92<\mathrm{X} \leq 2,64$ & Kurang \\
\hline 1 & $\mathrm{X} \leq 1,92$ & Sangat Kurang \\
\hline \multicolumn{4}{c}{ Sumber : Sukardjo, 2008 }
\end{tabular}

\section{HASIL PENELITIAN DAN PEMBAHASAN}

\section{Hasil Pengembangan multimedia pembelajaran}

Langkah awal dalam pengembangan multimedia pembelajaran adalah membuat desain pembelajaran. Dari langkah ini dihasilkan sebuah desain pembelajaran untuk mata kuliah tata rias wajah korektif. Analisis desain pembelajaran ini dimulai dari merumuskan tujuan umum, merumuskan tujuan khusus, mengembangkan instrumen penilaian, mengembangkan strategi instruksional dan mengembangkan materi/bahan pembelajaran. Berdasarkan analisis ini, maka dikembangkan silabus pembelajaran, Satuan Acara Perkuliahan (SAP), bahan/materi pembelajaran, dan alat evaluasi. Silabus pembelajaran terdiri dari satu standar kompetensi, dan lima 
kompetensi dasar. SAP terdiri dari lima pertemuan pembelajaran yang dikembangkan dari lima kompetensi dasar. Untuk materi/bahan pembelajaran berasal dari berbagai sumber, seperti dari modul pembelajaran tata rias wajah korektif yang sudah ada. Alat evaluasi yag digunakan berupa tes pilihan ganda dan lembar penilaian praktek.

Setelah desain pembelajaran dilakukan, maka tahap berikutnya adalah membuat desain produk multimedia pembelajaran dengan membuat storyboard dan flowchart, yang berisikan desain tampilan multimedia pembelajaran, gambar, video, musik dan tomboltombol yang digunakan, narasi dari multimedia pembelajaran yang dikembangkan.

Langkah selanjutnya, pelaksanaan produksi multimedia pembelajaran. dengan terlebih dahulu menginstal software yang dibutuhkan seperti adobe flash, adobe photoshop dan adobe premier. Setelah itu, dilakukan pembuatan image dan logo untuk tampilan multimedia dengan warna dasar pink (merah muda), melakukan pemilihan layout, pembuatan tombol dan pengisian content pada multimedia pembelajaran meliputi pengisian materi, gambar bentuk wajah dan bentuk bagian wajah serta koreksinya, narasi, video, musik, soal latihan serta penambahan fitur-fitur penunjang lainnya.

\section{Hasil evaluasi formatif}

Evaluasi formatif dilakukan oleh para ahli (expert judgment) untuk menilai kelayakan program multimedia pembelajaran yang dikembangkan. Penilaian ini akan menjadi dasar untuk memperbaiki program yang dinilai kurang baik oleh para ahli. Para ahli yang diminta menilai program multimedia pembelajaran ini adalah mereka yang memiliki latar belakang keahlian dalam bidang media pembelajaran, dan materi tata rias wajah korektif.

Para ahli yang mengevaluasi program multimedia pembelajaran ini di antaranya ahli media pembelajaran yaitu Cecep Kustandi M.Pd yang merupakan dosen di jurusan Teknologi Pendidikan Universitas Negeri Jakarta, sedangkan ahli materi tata rias wajah korektif adalah Nurina Ayuningtyas M. Pd yang merupakan dosen di program studi Tata Rias Universitas Negeri Jakarta. Evaluasi pakar ini merupakan uji kelayakan pertama yang dilakukan oleh pengembang, yang bertujuan untuk penyempurnaan produk agar dapat diuji coba pada tahap berikutnya.

Hasil evaluasi program multimedia pembelajaran oleh ahli media pembelajaran, mendapatkan skor ratarata 3,54 berarti program dinilai baik. Masukan dari ahli media diantaranya jenis huruf agar diganti, letak paragraf teks harus seimbang antara sis kiri dan kanan. Berikut ini disajikan hasil evaluasi oleh ahli media pembelajaran.

Tabel 2. Hasil Evaluasi Ahli Media

\begin{tabular}{clc}
\hline No & \multicolumn{1}{c}{ Aspek } & Rerata \\
\hline 1 & Isi/materi & 3,6 \\
\hline 2 & Karakteristik mahasiswa & 3,5 \\
\hline 3 & Interaksi mahasiswa & 3,5 \\
\hline 4 & Individual & 3,7 \\
\hline 5 & Minat mahasiswa & 3,4 \\
\hline 6 & Umpan balik & 3,6 \\
\hline 7 & Lingkungan belajar & 3,67 \\
\hline 8 & Komponen komputer & 3,4 \\
\hline & Skor akhir & $\mathbf{3 , 5 4}$ \\
\hline
\end{tabular}

Mengacu pada hasil evaluasi ahli media mengenai multimedia pembelajaran yang dikembangkan dapat disimpulkan bahwa multimedia pembelajaran layak digunakan pada tahap selanjutnya.

Hasil evaluasi oleh ahli materi terhadap program multimedia pembelajaran, mendapatkan skor rata-rata 3,60 yang berarti program ini dinilai baik. Masukan dari ahli materi adalah pada 
latihan agar memunculkan pilihan jawaban yang benar setelah jawaban dikoreksi selain umpan balik benar atau salah.

Tabel 3. Hasil evaluasi oleh ahli materi

\begin{tabular}{clc}
\hline No & \multicolumn{1}{c}{ Aspek } & Rerata \\
\hline 1 & $\begin{array}{l}\text { Kompetensi } \\
\text { dasar/Indikator }\end{array}$ & 3,67 \\
\hline 2 & Isi / Materi & 3,11 \\
\hline 3 & karakteristik mahasiswa & 3,33 \\
\hline 4 & Minat mahasiswa & 4 \\
\hline 5 & Pendekatan & 3,2 \\
\hline 6 & Umpan Balik & 4 \\
\hline 7 & Lingkungan belajar & 4 \\
\hline 8 & Evaluasi & 3,5 \\
\hline & Rata-rata keseluruhan & $\mathbf{3 , 6 0}$ \\
\hline
\end{tabular}

Secara umum mengacu pada hasil evaluasi ahli materi mengenai multimedia pembelajaran yang dikembangkan dapat disimpulkan bahwa materi yang disajikan dalam program multimedia pembelajaran dengan kategori baik. Hal ini berarti dilihat dari segi materi, materi yang disajikan memadai untuk memberikan pengetahuan dan pemahaman awal kepada mahasiswa terhadap materi tata rias wajah korektif yang dipelajari dan diaplikasikan pada mata kuliah tata rias wajah korektif di program studi Tata Rias Universitas Negeri Jakarta.

Setelah dilakukan revisi berdasarkan hasil evaluasi dan masukan dari para ahli, langkah selanjutnya dari proses pengembangan ini adalah melakukan uji coba satu-satu kepada mahasiswa program studi Tata Rias Universitas Negeri Jakarta. Uji coba ini dimaksudkan untuk mengetahui kelayakan multimedia pembelajaran. Uji coba dilakukan terhadap 3 orang mahasiswa tata rias. Pengembang meminta mahasiswa untuk memberikan komentar dengan leluasa tentang program multimedia pembelajaran. Mahasiswa diminta mencatat, mengamati, mencermati dan mendiskusikan program multimedia pembelajaran yang sedang mereka pelajari.
Uji coba dilakukan dengan dua cara yaitu melalui penyebaran angket dan wawancara satu per satu. Data yang diperoleh melalui penyebaran angket dapat digambarkan sebagai berikut:

Tabel 4. Hasil Uji Coba Satu-Satu

\begin{tabular}{clc}
\hline No & \multicolumn{1}{c}{ Aspek } & Rerata \\
\hline 1 & $\begin{array}{l}\text { Kompetensi } \\
\text { dasar/indikator }\end{array}$ & 3 \\
\hline 2 & Isi/materi & 2,6 \\
\hline 3 & Interaksi mahasiswa & 3 \\
\hline 4 & Individual & 2,5 \\
\hline 5 & Minat mahasiswa & 2,8 \\
\hline 6 & Umpan balik & 2,8 \\
\hline 7 & Lingkungan belajar & 3 \\
\hline 8 & Evaluasi & 2,9 \\
\hline 9 & Komponen komputer & 3 \\
\hline & Rata-rata keseluruhan & $\mathbf{2 , 8 4}$ \\
\hline
\end{tabular}

Secara umum pada uji coba satusatu diperoleh hasil bahwa multimedia pembelajaran yang dikembangkan dapat dikatakan cukup baik dengan rata-rata nilai keseluruhan 2,84 .

Pada uji coba satu-satu ini mendapatkan masukan dari mahasiswa mengenai suara narator dan backsound, ada beberapa yang terdengar kurang keras, untuk itu dilakukan perbaikan agar suara narator dan backsound terdengar lebih keras. Mengenai petunjuk penggunaan program diperjelas lagi karena ada beberapa langkah petunjuk penggunaan tidak diberi panah pada gambar. Semua masukan tersebut telah diperbaiki.

Setelah dilakukan revisi terhadap masukan dan saran dari uji coba satu-satu, maka dilakukan uji coba kelompok kecil. Uji coba ini bertujuan untuk menggali informasi dan masukan dari mahasiswa mengenai multimedia pembelajaran dan menekankan pada kejelasan dan keefektifan setiap aspek pada program multimedia pembelajaran.

Uji coba dilakukan pada 8 orang mahasiswa program studi Tata Rias Universitas Negeri Jakarta. Mahasiswa diminta untuk menggunakan multimedia 
pembelajaran tata rias wajah korektif, setelah itu diminta untuk mengisi angket dan dilakukan wawancara terbuka mengenai program multimedia pembelajaran yang telah mereka gunakan.

Secara umum pada tahap uji coba kelompok kecil diperoleh hasil bahwa multimedia pembelajaran yang dikembangkan dapat dikatakan cukup baik dengan rata-rata nilai keseluruhan 3,16. Selain itu, data yang diperoleh melalui penyebaran angket pada uji coba kelompok kecil dapat digambarkan sebagai berikut:

Tabel 5. Hasil Uji Coba Kelompok Kecil

\begin{tabular}{clc}
\hline No & \multicolumn{1}{c}{ Aspek } & Rerata \\
\hline 1 & $\begin{array}{l}\text { Kompetensi } \\
\text { dasar/indikator }\end{array}$ & 3 \\
\hline 2 & Isi/ materi & 3 \\
\hline 3 & Interaksi mahasiswa & 3,1 \\
\hline 4 & Individual & 3,3 \\
\hline 5 & Minat mahasiswa & 3,2 \\
\hline 6 & Umpan balik & 3,4 \\
\hline 7 & Lingkungan belajar & 3,3 \\
\hline 8 & Evaluasi & 3,13 \\
\hline 9 & Komponen komputer & 3 \\
\hline & Rata-rata keseluruhan & $\mathbf{3 , 1 6}$ \\
\hline
\end{tabular}

\section{Hasil Uji Coba Efektifitas Multimedia Pembelajaran}

Uji coba lapangan dilakukan untuk mengetahui efektifitas multimedia pembelajaran tata rias wajah korektif yang dikembangkan. Efektifitas diukur dengan hasil belajar (pre-test dan posttest) pada ranah kognitif dan psikomotorik dengan menetapkan skor minimum pencapai kompetensi sebesar 75 (tujuh puluh lima). Uji coba dilakukan terhadap 18 orang mahasiswa yang belum mendapatkan materi tata rias wajah korektif. Uji coba dilakukan melalui langkah-langkah di antaranya sebelum diberi penjelasan mengenai pembelajaran menggunakan multimedia pembelajaran tata rias wajah koreksi, mahasiswa diberikan pretest. Mahasiswa diminta untuk menjawab beberapa pertanyaan yang ada pada lembar soal. Hasil dari pretest mengindikasikan bahwa materi pelajaran benar-benar dibutuhkan oleh mahasiswa untuk menambah pemahaman dan pengetahuan tentang tata rias wajah korektif. Informasi ini dapat disimpulkan dari skor yang didapatkan oleh 18 orang peserta yang mengikuti pre-test untuk menilai ranah kognitif dengan skor ratarata 53,13 dari 100 skor tertinggi. Pencapaian angka ini dapat dikategorikan rendah. Selain itu pada pre-test untuk menilai ranah psikomotorik, rata-rata nilai yang didapatkan 76,67 , nilai ini dapat dikategorikan cukup.

Setelah mengerjakan pretest, mahasiswa diberi penjelasan untuk selanjutnya mengikuti pembelajaran dengan menggunakan multimedia pembelajaran tata rias wajah korektif. Materi tata rias wajah korektif didapatkan mahasiswa dengan mengoperasikan multimedia pembelajaran tata rias wajah korektif pada komputer yang disediakan, petunjuk penggunaan multimedia pembelajaran tata rias wajah korektif dapat dipelajari pada buku petunjuk penggunaan multimedia pembelajaran tata rias wajah korektif yang diberikan pada masing-masing mahasiswa.

Mahasiswa diberikan waktu selama 5 kali pertemuan masing-masing 30 menit untuk mempelajari setiap pokok bahasan yang terdapat pada multimedia pembelajaran dan mengerjakan soal latihan. Pada pertemuan ke 5, mahasiswa harus sudah mempelajari semua pokok bahasan dan latihan yang ada pada setiap pertemuan. Mahasiswa diminta mengerjakan post-test. Dari hasil post-test untuk menilai ranah kognitif didapatkan skor rata-rata 80,62 dan hasil postest untuk menilai ranah psikomotorik didapatkan nilai rata-rata 81,01. Pencapaian angka ini dapat dikategorikan baik dan menunjukkan terdapat peningkatan hasil belajar setelah menggunakan multimedia pembelajaran tata rias wajah korektif. Selain itu, mahasiswa mengapresiasi 
pembelajaran dengan menggunakan multimedia pembelajaran karena sangat menambah wawasan pengetahuan, keterampilan dan memotivasi dalam pembelajaran.

\section{SIMPULAN}

Berdasarkan hasil penelitian dan pengembangan dapat disimpulkan bahwa pengembangan produk multimedia pembelajaran tata rias wajah korektif telah diselesaikan dengan menggunakan beberapa langkah pengembangan dan evaluasi. Proses desain adalah langkah awal memulai pengembangan, yaitu pengumpulan data, sasaran, materi dan komponen penunjang lainnya. Proses kedua adalah produksi, dimana semua bahan yang telah dikumpulkan disusun dalam sebuah produk awal.

Proses berikutnya adalah evaluasi oleh ahli materi dan ahli media, uji coba satu-satu, uji coba kelompok kecil dan uji coba lapangan. Dari hasil evaluasi oleh ahli materi dan ahli media, masingmasing memberikan saran yang kemudian dijadikan masukan untuk memperbaiki multimedia. Hasil penilaian oleh ahli materi dengan skor 3,60 dan ahli media dengan 3,54 yang menunjukkan multimedia dinilai baik. Pada uji coba satu-satu dengan 3 orang mahasiswa tata rias didapatkan skor 2,84 yang menunjukkan multimedia dinilai cukup baik. Pada uji coba kelompok kecil dengan 8 orang mahasiswa didapatkan skor akhir 3,16 yang menunjukkan multimedia dinilai baik. Pada uji coba lapangan dengan 18 orang mahasiswa didapatkan rerata nilai pre-test dan posttest pada ranah kognitif dan ranah psikomotorik. Pada ranah kognitif terdapat rerata nilai pre-test sebesar 53,13 dan rerata nilai post-test sebesar 80,62. Pada ranah psikomotorik terdapat rerata nilai pre-test 76,72 dan rerata nilai posttest 81,01. Secara umum multimedia pembelajaran tata rias wajah koreksi yang dihasilkan dinilai baik untuk pembelajaran dan dapat menambah wawasan mahasiswa mengenai tata rias wajah koreksi.

\section{Saran}

Saran dalam penelitian yang berkenaan dengan pengembangan multimedia pembelajaran tata rias wajah korektif ini dan untuk penelitian selanjutnya antara lain: (1) Uji lapangan terhadap program multimedia pembelajaran tata rias wajah korektif untuk diuji kepada skala yang lebih besar, tidak hanya di program studi program studi Tata Rias Universitas Negeri Jakarta, tetapi juga di Universitas/ Sekolah Tinggi lain yang membuka program keahlian Tata Rias, agar efektifitas program benar-benar teruji dengan layak. (2) Penilaian pada ranah afektif sebaiknya dilakukan karena hal ini akan mempengaruhi sikap mahasiswa yang nantinya akan menjadi pendidik.

\section{DAFTAR PUSTAKA}

Dick, W., Carey, L., \& Carey, J. O. (2005). The Systematic Design of Instruction, Sixth Edition. Boston: Pearson.

Hannafin, M. J. \& Peck, K. L. (1988). The Design, Development, and Evaluation of Instructional Software. New York: Macmillan Publishing Company.

Miarso, Y. (2004). Menyemai Benih Teknologi Pendidikan. Jakarta: Prenada Media.

Republik Indonesia. (2003). Undangundang RI Nomor 20 tahun 2003, tentang Sistem Pendidikan Nasional.

Sadiman, A., Rahardjo, Haryono, A., dan Rahardjito. (2009). Media Pendidikan, Pengertian, Pengembangan dan 
Pemanfaatannya. Jakarta: Raja Grafindo Persada.

Smaldino, S. E., Lowther, D. L. dan Russel, J. D. (2008). Instructional Technology and Media for Learning $9^{\text {th }}$ ed. Upper Saddle River, New Jersey: Pearson Education, Inc.

Sukardjo. (2008). Hand Out Materi Evaluasi Pembelajaran.
Yogyakarta: Jurusan Teknologi Pembelajaran, Program Pascasarjana Universitas Negeri Yogyakarta

Supiani, T. (2013). Silabus Perkuliahan Tata Rias Wajah Korektif. Program Studi Tata Rias Universitas Negeri Jakarta.

Vaughan, T. (2006). Multimedia: Make It Work. Osborn: McGraw-Hill. 